\title{
PREVALÊNCIA DE HEMOGLOBINA S EM DOADORES DE SANGUE NA CIDADE DE MARINGÁ-PR
}

\author{
BAHU, Laiza Gava ${ }^{1}$ \\ FERNANDES, Talma Reis Leal ${ }^{2}$
}

Recebido em: 2019.12 .09

Aprovado em: 2020.04.20

ISSUE DOI: $10.3738 / 1982.2278 .3724$

\begin{abstract}
RESUMO: As doenças falciformes englobam um grupo de anemias hemolíticas hereditárias que têm em comum a presença intra-eritrocitária de uma hemoglobina variante, a HbS. Os indivíduos heterozigotos assintomáticos podem transmitir o gene mutado sem saberem, assinalando um importante problema de saúde pública. Portanto, o objetivo deste estudo foi avaliar a frequência de $\mathrm{HbS}$ em doadores de um banco de sangue privado da cidade de Maringá, Paraná. O estudo foi descritivo e retrospectivo, no período de janeiro de 2004 a dezembro de 2017, analisando os registros de prontuários dos doadores de sangue aptos após triagem clínica. Dos 55.941 indivíduos avaliados, 1,36\% apresentaram resultado positivo para $\mathrm{HbS}$; a maioria caucasianos/brancos do sexo masculino e com idade acima de 29 anos. Ficou evidenciada associação estatística entre o grau de escolaridade e a periodicidade da doação. Foi observada pequena diminuição da frequência de $\mathrm{HbS}$ nos doadores nos últimos três anos. Os resultados demonstraram a influência do contexto histórico na dinâmica populacional e no perfil genético da população estudada, confirmando o comportamento de miscigenação racial na região. O predomínio de indivíduos do sexo masculino e com mais de 29 anos refletiu o perfil do doador de sangue no Brasil. Os portadores do traço falciforme com maior grau de escolaridade doaram sangue com mais frequência, provavelmente por terem mais acesso às informações. A diminuição percentual mínima da ocorrência de HbS nos últimos três anos demonstra a eficácia das políticas públicas em relação as doenças falciformes, principalmente a triagem nos centros de referência de doação de sangue.
\end{abstract}

Palavras-chave: Hemoglobinopatias; Anemia falciforme; Traço falciforme; Aconselhamento genético.

\section{PREVALENCE OF HEMOGLOBIN S IN BLOOD DONORS IN THE CITY OF MARINGÁ-PR}

\begin{abstract}
SUMMARY: Sickle diseases encompass a group of hereditary hemolytic anemias that have in common the intraerythrocyte presence of a variant hemoglobin, HbS. Asymptomatic heterozygous individuals may transmit the mutated gene unknowingly, signaling an important public health problem. Therefore, the objective of this study was to evaluate the frequency of $\mathrm{HbS}$ in donors from a private blood bank in the city of Maringá, Paraná. The study was descriptive and retrospective, from January 2004 to December 2017, analyzing the medical record records of eligible blood donors after clinical screening. Of the 55.941 individuals evaluated, $1.36 \%$ presented a positive result for $\mathrm{HbS}$; mostly white/caucasian males over the age of 29. A statistical association between the degree of schooling and the periodicity of the donation was evidenced. There has been a small decrease in the frequency of HbS in donors in the last three years. The results demonstrated the influence of the historical context on the population dynamics and the genetic profile of the studied population, confirming the racial miscegenation behavior in the region. The prevalence of males over 29 years of age reflected the profile of blood donors in Brazil. Those with sickle cell trait with higher education gave blood more often, probably because they had more access to information. The minimal percentage decrease in the occurrence of $\mathrm{HbS}$ in the last three years demonstrates the effectiveness of public policies regarding sickle cell diseases, especially screening in blood donor referral centers.
\end{abstract}

Keywords: Hemoglobinopathies; Sickle cell; Sickle cell trait; Genetic counseling.

\footnotetext{
${ }^{1}$ Acadêmica do Curso de Farmácia da UNICESUMAR.

2* Professora Doutora do Curso de Farmácia da UNICESUMAR.

* Centro de Ciências Biológicas e da Saúde, Centro Universitário de Maringá - Unicesumar - Av. Guedner, 1610, Jardim Aclimação, Maringá, Paraná. Brasil. CEP: 87050-390. talma.fernandes@ unicesumar.edu.br
} 


\section{INTRODUÇÃO}

A hemoglobina $\mathrm{S}$ (Sickle - $\mathrm{HbS}$ ) é uma variante de hemoglobina A (HbA) normal, originária de uma mutação do gene $\beta$-globínico em que ocorre a troca da base nitrogenada adenina pela timina $(\mathrm{GAG} \rightarrow \mathrm{GTG})$, resultando na substituição de ácido glutâmico pela valina na posição 6 da extremidade N-terminal da cadeia beta da globina (ANVISA, 2002; GUIMARÃES; COELHO, 2010; GIBSON; REES, 2016; REZENDE, 2017).

Os indivíduos homozigotos - SS $\left(\beta^{\mathrm{S}} \beta^{\mathrm{S}}\right)$ desenvolvem anemia falciforme, enquanto os heterozigotos são portadores de um único gene afetado, produzindo $\mathrm{HbA}$ e $\mathrm{HbS}-\mathrm{AS}\left(\beta^{\mathrm{A}} \beta^{\mathrm{S}}\right)$ (traço falciforme ou falcêmico). Pode acontecer a heterozigose dupla da $\mathrm{HbS}$ com outras hemoglobinas variantes como no caso da hemoglobinopatia SC (HbSC), doença SD (HbSDPunjab) ou ainda, interações com as talassemias $S \beta^{0}$ (Tal $S \beta^{0}$ - não há produção de $\left.\mathrm{HbA}\right), \mathrm{S} / \beta^{+}$ (Tal $S / \beta^{+}$- há pouca quantidade de $\mathrm{HbA}$ associada a $\left.\mathrm{HbS}\right), \mathrm{S} / \alpha(\mathrm{HbS} / \alpha \mathrm{Tal})$ e $\mathrm{S} / \beta(\mathrm{Hb} \mathrm{S} / \beta)$. Há também a anemia falciforme associada à persistência hereditária de hemoglobina fetal (HbS/PHHF) (ANVISA, 2002; RUIZ JÚNIOR, 2009; AQUINO et al., 2014; MACHADO, 2014; MONTEIRO et al., 2015).

No conjunto, todas as formas sintomáticas do gene da HbS, em homozigose ou em combinação, são conhecidas como doenças falciformes e apresentam um espectro epidemiológico e de manifestações clínicas e hematológicas superponíveis (ANVISA, 2002).

A HbS oxigenada é muito menos solúvel que a $\mathrm{HbA}$; deste modo, sob determinadas condições de desoxigenação, as moléculas de $\mathrm{HbS}$ se polimerizam em feixes paralelos, provocando deformações das hemácias que assumem forma de foice, com consequente enrijecimento e encurtamento de sua vida média. Essas células expressam maior número de moléculas de adesão na superfície externa da membrana celular que hemácias normais, o que favorece a interação com o endotélio e com outras células, causando vaso-oclusão. Desta maneira, essas hemácias acabam provocando uma obstrução do fluxo sanguíneo e são destruídas precocemente, principal causa da anemia (MORAES; GALIOTI, 2010; QUIARATI; ZANUSSO JUNIOR, 2015; SOUZA et al., 2016).

Geralmente quanto maior a quantidade de $\mathrm{HbS}$, mais grave é a doença. Por isso os portadores de HbAS e os HbS/PHHF são assintomáticos, não apresentando hemólise e crises de falcização. A presença de outras hemoglobinas dentro da hemácia causa um "efeito de diluição", diminuindo a oportunidade de contato e constituição do polímero. O aspecto realmente preocupante é que esses indivíduos assintomáticos podem transmitir o gene mutado para seus 
filhos sem saberem (ANVISA, 2002; BATISTA; ANDRADE, 2005; SILVA et al., 2012; GIBSON; REES, 2016).

No Brasil há mais de 2 milhões de portadores do gene da hemoglobina $\mathrm{S}$, com a forma homozigótica superior a 8 mil casos; estimando ainda o nascimento de setecentos a mil novos casos de doenças falciformes por ano. Em virtude dessa elevada frequência de indivíduos com gene para hemoglobina $\mathrm{S}$ em nosso país, políticas públicas vêm sendo implementadas com o objetivo de prestar assistência aos portadores dessas hemoglobinopatias e orientação genética às pessoas com traço falciforme (RAMALHO; GIRALDI; MAGNA, 2008; BONZO, 2013).

O Ministério da Saúde (MS) criou, em 1996, o Programa de Anemia Falciforme (PAF) com informações relativas a doença e aos seus aspectos hereditários, com vasta distribuição de folhetos explicativos. Esse processo foi amplamente reforçado pela Agência Nacional de Vigilância Sanitária (ANVISA) a partir de 2002, com o guia do paciente, o guia do professor, o guia do médico, etc. (RAMALHO; GIRALDI; MAGNA, 2008).

Outra estratégia de grande importância foi a implementação da Portaria 822/01 do Ministério da Saúde, de 06 de Junho de 2001 que incluiu a anemia falciforme e outras hemoglobinopatias no Programa Nacional de Triagem Neonatal (PNTN), com intuito de diagnóstico precoce, acompanhamento multiprofissional e tratamento dos indivíduos acometidos (MORAES; GALIOTI, 2010; VIEIRA, 2016).

Em junho de 2004 a Resolução da Diretoria Colegiada da Agência Nacional de Vigilância Sanitária RDC 153/04 tornou obrigatória a triagem de hemoglobinopatias nos doadores de sangue do Brasil, melhorando cada vez mais a qualidade do sangue a ser transfundido. Embora os portadores do traço falciforme não apresentem alterações clínicas e hematológicas e estejam aptos à doação de sangue, há restrições. A Portaria nº 158 de 04 de Fevereiro de 2016 reforçou esse aspecto. Os componentes eritrocitários de doadores positivos para $\mathrm{HbS}$ devem conter essa informação em seu rótulo e não devem ser desleucocitados e nem utilizados em pacientes com hemoglobinopatias, com acidose grave, em recém-nascidos, pacientes de transfusão intra-uterina, de procedimentos cirúrgicos com circulação extracorpórea e com hipotermia. Caso necessário, o doador portador do traço falcêmico deve ser orientado e encaminhado ao serviço assistencial para avaliação clínica (SILVA; GIOVELLI, 2010; VIEIRA, 2016; BERNIERI; FIOR; ARDENGHI, 2017).

Quando o traço falciforme é detectado, faz-se uma rotina de aconselhamento no próprio centro de doação pelo médico hematologista. A triagem beneficia tanto o doador quanto o receptor. Primeiramente, protege o receptor de receber hemácias anômalas que não podem cumprir seu papel, tornando a transfusão ineficiente. Por sua vez, a identificação do traço falciforme e aconselhamento genético no doador é de grande importância para saúde pública, 
pois, pode evitar a propagação do gene da $\mathrm{HbS}$, tanto como possível fonte de novos heterozigotos, como por originar novos casos de anemia falciforme (DINIZ; GUEDES, 2005; SILVA; GIOVELLI, 2010).

Devido o aspecto hereditário da doença falciforme e o impacto sobre a família dos indivíduos acometidos e a sociedade, o desenvolvimento de estudos que caracterizem a ocorrência de indivíduos portadores de $\mathrm{HbS}$ é de extrema relevância, com o fornecimento de dados que auxiliem no desenvolvimento de políticas públicas a serem adotadas para reduzir a prevalência dessas patologias no Brasil.

Diante do exposto, o objetivo deste estudo foi avaliar a frequência de hemoglobina $\mathrm{S}$ em doadores de sangue de um banco de sangue privado da cidade de Maringá, Paraná. Além de correlacionar a positividade a $\mathrm{HbS}$ com as variáveis: sexo, etnia, faixa etária e grau de escolaridade.

\section{METODOLOGIA}

Trata-se de um estudo descritivo e retrospectivo que analisou a frequência da hemoglobina variante $\mathrm{S}$ a partir dos registros de prontuários dos doadores de sangue aptos após triagem clínica, de em banco de sangue privado da cidade de Maringá-Pr. A amostra incluiu indivíduos de ambos os sexos, de 16 a 69 anos que realizaram doação de sangue no período de janeiro de 2004 a dezembro de 2017.

A Resolução da Diretoria Colegiada da Agência Nacional de Vigilância Sanitária RDC 153/04 de Junho de 2004 embora exija a triagem de hemoglobinopatias em doadores de sangue, não define o método de diagnóstico de detecção que deve ser realizado (SILVA; GIOVELLI, 2010; REZENDE, 2017).

$\mathrm{O}$ banco de sangue em questão utiliza um teste qualitativo para a triagem de $\mathrm{HbS}$, o teste de solubilidade, no qual as hemácias são lisadas e a $\mathrm{Hb}$ S é reduzida pelo ditionito de sódio; por ser insolúvel, ela forma polímeros de deoxi-HbS com esse reagente e turva a solução, enquanto que as soluções contendo outras hemoglobinas permanecem sem turvação. Os resultados positivos são confirmados por outro teste qualitativo, o de falcização. Este teste utiliza o metabissulfito de sódio como substância redutora, a qual em contato com as hemácias extrai o oxigênio, levando as hemácias com $\mathrm{HbS}$ a assumir o formato de foice, verificado pela observação das hemácias ao microscópio (SILVA; GIOVELLI, 2010).

Dos prontuários dos indivíduos que apresentaram resultados positivos para $\mathrm{HbS}$ foram avaliadas as seguintes variáveis independentes: sexo, faixa etária, etnia, grau de escolaridade e 
periodicidade da doação de acordo com a Portaria Ministerial n ${ }^{0}$ 158/2016 (BRASIL, 2016).

O presente estudo foi aprovado pelo Comitê de Ética e Pesquisa do UniCesumar (CEP) com Parecer $n^{0}$ 2.714.268/2018.

Os dados obtidos foram digitados em planilha do programa Microsoft Excel 2010 e analisados estatisticamente com o auxílio do Software Statistica Single User versão 13.2.

$\mathrm{Na}$ análise descritiva dos dados, os resultados foram apresentados em gráficos e tabelas simples. Já para avaliar possíveis associações entre periodicidade da doação e o grau de escolaridade, utilizou-se tabela de dupla entrada seguidas do teste qui-quadrado, cujo nível de significância adotado foi de $5 \%$, ou seja, foram consideradas significativas as comparações de $\mathrm{p}<0,05$.

\section{RESULTADO}

Um total de 138.614 doações ocorreu entre 2004 a 2017. Devido repetição da doação por um mesmo indivíduo, o banco de sangue registrou 55.941 doadores, dos quais 761 (1,36\%) apresentaram resultado positivo para $\mathrm{HbS}$ (Figura 1).

Figura 1: Prevalência de HbS em doadores de sangue de um Banco de Sangue privado da cidade de Maringá-Pr, no período de 2004 a 2017.

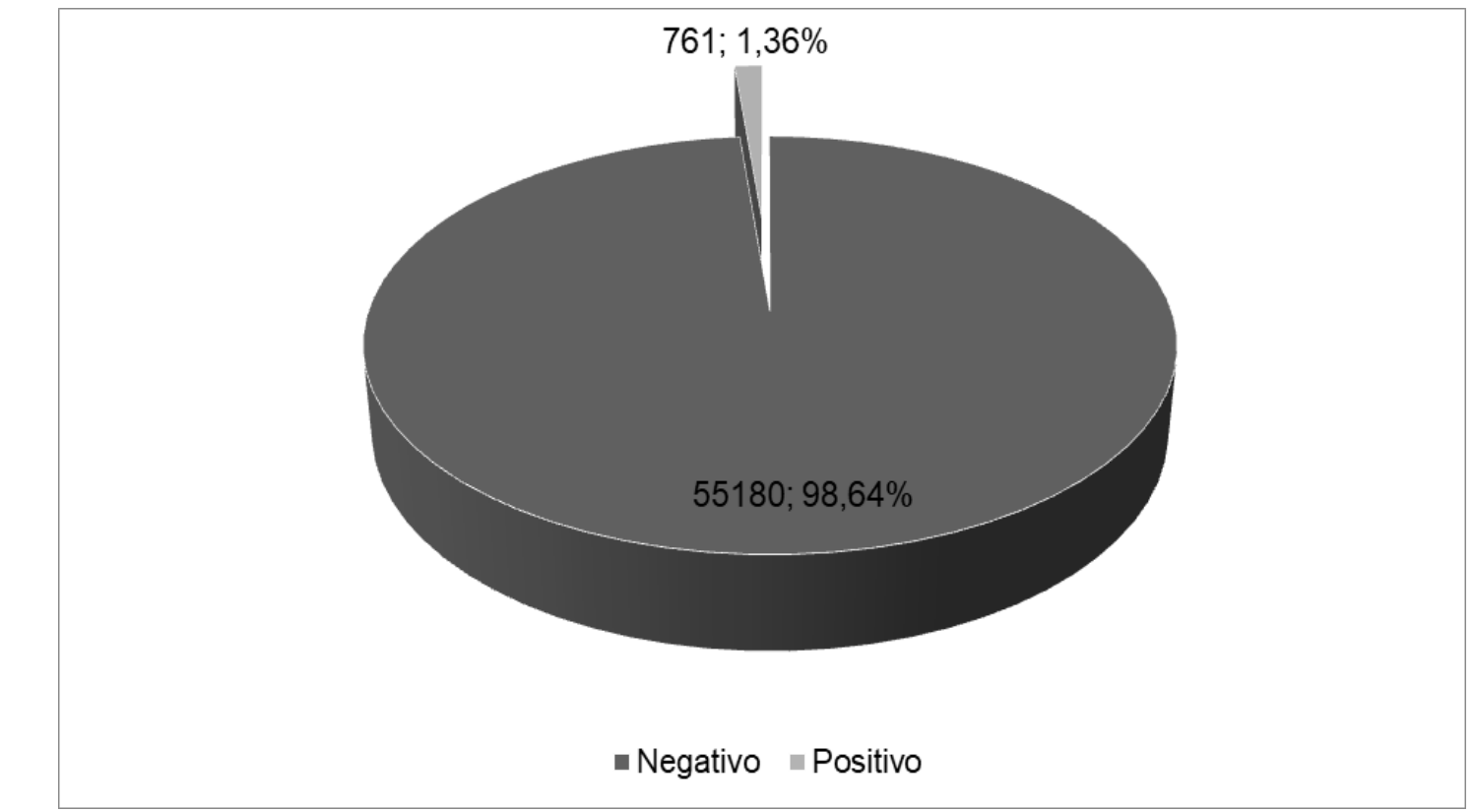

Fonte: Elaborado pelo Autor

Como se verifica na Tabela 1 , dos doadores positivos para $\mathrm{HbS}, 55,8 \%(\mathrm{n}=425)$ eram do sexo masculino e 44,2\% $(n=336)$ do sexo feminino, $74,5 \% \quad(n=567)$ pertenciam a raça 
caucasiana/branca, 39,2\% $(n=298)$ afirmaram ter $2^{\circ}$ grau completo e a faixa de idade mais prevalente, com 65\% $(\mathrm{n}=495)$ foi acima de 29 anos.

Em relação a periodicidade da doação, a maioria dos indivíduos $(50,3 \%, \mathrm{n}=383)$ era doador pela primeira vez, entretanto, mesmo conhecendo sua condição, 35,7\% ( $\mathrm{n}=272)$ doavam sangue esporadicamente (após intervalo superior a 12 meses da última doação) e 13,9\% (n=106) eram doadores de repetição (realizavam duas ou mais doações no período de 12 meses) (Tabela $1)$.

Tabela 1. Distribuição dos doadores de sangue portadores de $\mathrm{HbS}$, de acordo com o perfil, no período de 2004 a 2017.

\begin{tabular}{|c|c|c|}
\hline Perfil & $\mathbf{n}$ & $\%$ \\
\hline \multicolumn{3}{|c|}{ Gênero } \\
\hline Feminino & 336 & 44,2 \\
\hline Masculino & 425 & 55,8 \\
\hline \multicolumn{3}{|l|}{ Raça } \\
\hline Caucasiana/Branca & 567 & 74,5 \\
\hline Negra & 92 & 12,1 \\
\hline Parda & 102 & 13,4 \\
\hline \multicolumn{3}{|c|}{ Escolaridade } \\
\hline $1^{\circ}$ Grau completo & 72 & 9,5 \\
\hline $1^{\circ}$ Grau incompleto & 145 & 19,1 \\
\hline $2^{\circ}$ Grau completo & 298 & 39,2 \\
\hline $2^{\circ}$ Grau incompleto & 71 & 9,3 \\
\hline Nível superior incompleto & 84 & 11,0 \\
\hline Nível superior completo & 82 & 10,8 \\
\hline Sem alfabetização & 9 & 1,2 \\
\hline \multicolumn{3}{|c|}{ Faixa de idade } \\
\hline 16 a 29 anos & 266 & 35,0 \\
\hline Acima de 29 anos & 495 & 65,0 \\
\hline \multicolumn{3}{|c|}{ Periodicidade da doação } \\
\hline Primeira vez & 383 & 50,3 \\
\hline Esporádico & 272 & 35,7 \\
\hline Repetição & 106 & 13,9 \\
\hline
\end{tabular}

No período estudado, 2005, 2006, 2012 e 2013 foram os anos em que ocorreu maior prevalência de $\mathrm{HbS}$ com 1,6\% em 2005 e 1,5\% nos demais anos; e, a menor prevalência $(1,1 \%)$ foi observada em 2017, com tendência ao declínio a partir de 2015 (Figura 2). 
Figura 2. Distribuição anual de casos positivos de $\mathrm{HbS}$ entre os doadores de sangue no período de 2004 a 2017.

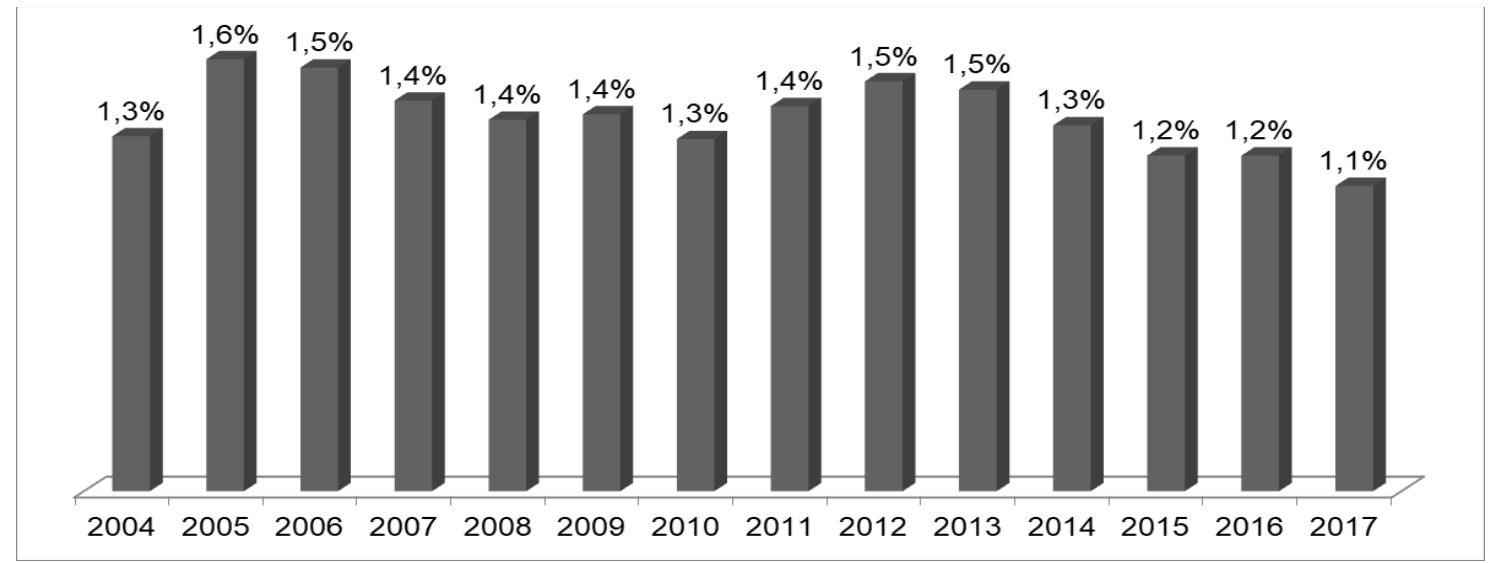

Fonte: Elaborado pelo Autor

Ficou evidenciada associação estatística entre o grau de escolaridade $(p=0,0163)$ com a periodicidade da doação, como se verifica na Tabela 2. Ao avaliarmos os indivíduos com menor escolaridade (sem alfabetização, com $1^{\circ}$ grau completo ou incompleto e com $2^{\circ}$ grau incompleto) verificamos que as doações esporádicas ou de repetição são significativamente menores $(18,0 \%)$ em relação aqueles com maior nível de escolaridade $\left(2^{\circ}\right.$ grau completo, nível superior completo ou incompleto) que somam $31,6 \%$.

Tabela 2. Relação do grau de escolaridade dos doadores com a periodicidade da doação, no período de 2004 a 2017.

\begin{tabular}{|c|c|c|c|c|c|c|c|}
\hline \multirow{3}{*}{ Variáveis } & \multicolumn{6}{|c|}{ Periodicidade da doação } & \multirow{3}{*}{$\mathbf{p}$} \\
\hline & \multicolumn{2}{|c|}{ Primeira vez } & \multicolumn{2}{|c|}{ Esporádico } & \multicolumn{2}{|c|}{ Repetição } & \\
\hline & $\mathbf{N}$ & $\%$ & $\mathbf{n}$ & $\%$ & $\mathbf{n}$ & $\%$ & \\
\hline \multicolumn{7}{|l|}{ Escolaridade } & \multirow{8}{*}{$0,0163 *$} \\
\hline $1^{\circ} \mathrm{Grau}$ completo & 38 & 5,0 & 28 & 3,7 & 6 & 0,8 & \\
\hline $1^{\circ} \mathrm{Grau}$ incompleto & 81 & 10,6 & 46 & 6,0 & 18 & 2,4 & \\
\hline $2^{\circ}$ Grau completo & 142 & 18,7 & 108 & 14,2 & 48 & 6,3 & \\
\hline $2^{\circ}$ Grau incompleto & 35 & 4,6 & 23 & 3,0 & 13 & 1,7 & \\
\hline Nível superior incompleto & 49 & 6,4 & 27 & 3,5 & 8 & 1,1 & \\
\hline Nível superior completo & 32 & 4,2 & 39 & 5,1 & 11 & 1,4 & \\
\hline Sem alfabetização & 6 & 0,8 & 1 & 0,1 & 2 & 0,3 & \\
\hline
\end{tabular}

*p valor significativo pelo teste qui-quadrado considerando nível de significância de $5 \%$.

Fonte: Elaborado pelo Autor

\section{DISCUSSÃO}

Segundo Ferreira; Silveira-Lacerda; García-Zapata (2014), aproximadamente 7\% da população mundial apresenta hemoglobinopatias, estimando-se que no Brasil $4 \%$ da população possua o traço falciforme. Guimarães e Coelho (2010) são mais específicos em afirmar que esta 
condição genética afeta 6 a 10\% dos indivíduos de etnia negra e cerca de $1 \%$ da população em geral no país.

Acredita-se que a elevada prevalência da hemoglobinopatia $S$ na população negra se deva a séculos de processo de seleção natural, pela maior resistência dos eritrócitos contendo HbS à infecção pelo Plasmodium sp (KRAWCZYK et al., 2014; MACHADO, 2014; MONTEIRO et al., 2015; REZENDE, 2017).

Batista e Andrade (2005), estudando a anemia falciforme no Brasil, relataram que a hemoglobinopatia AS na região sudeste tem prevalência média de $2 \%$, sendo a maior frequência observada nas regiões norte e nordeste, pela maior proporção de antepassados negros na população. Estes autores descreveram trabalhos em diversos estados do país, como estudo preventivo das hemoglobinopatias anormais realizado no Rio de Janeiro com 3.345 pacientes em instituições públicas e bancos de sangue que detectou ser a hemoglobinopatia AS a mais frequente $(2,86 \%)$ em todos os locais de coleta. Em Pernambuco foi encontrada frequência de $5,1 \%$ de traço falciforme em recém-nascidos no Instituto Materno Infantil (IMIP). No Centro da Fundação de Hemoderivados de Minas Gerais, pesquisa também realizada em recém-nascidos, detectou 3,41\% de positividade para HbS. Já, trabalho semelhante realizado em Porto Alegre, indicou 1,2\% de frequência para portadores do gene da doença falciforme. Santos et al. (2015) encontraram $1,68 \%$ do genótipo AS em pesquisa no Ceará.

De fato, muitos autores concordam que, apesar da predominância do traço falciforme em áreas onde há mais indivíduos da raça negra, ele é encontrado em todas as regiões brasileiras devido o processo de miscigenação, alertando que estudos populacionais têm mostrado crescente a presença de $\mathrm{HbS}$ em indivíduos caucasoides (BATISTA; ANDRADE, 2005; GUIMARÃES; COELHO, 2010; KRAWCZYK et al., 2014; JESUS; SANTANA, 2015).

Neste trabalho constatou-se presença de $\mathrm{HbS}$ em 1,36\% da população estudada, destes, $74,5 \%$ eram caucasianos/brancos. Estes resultados refletem a colonização e ocupação da região noroeste do Paraná a partir do século XX. Embora a cidade de Maringá tenha recebido imigrantes de todos os estados brasileiros, neste período a expansão cafeeira atraiu principalmente paulistas e descendentes de italianos e alemães provenientes do Rio Grande do Sul e oeste de Santa Catarina. Posteriormente vieram descendentes de outras nacionalidades, incluindo os japoneses (PEDRO; PRIORI, 2010).

Quiarati e Zanusso Junior (2015) realizaram pesquisa semelhante, mas, em população afrodescendente da cidade de Maringá e comparativamente, evidenciaram maior prevalência (2\%) de HbS nas amostras coletadas. Os dados apresentados corroboram com os relatos dos 
pesquisadores anteriormente citados e com nosso trabalho, reforçando o caráter étnico dessa hemoglobinopatia e o alto grau de miscigenação da população brasileira.

Ainda, quanto ao perfil dos doadores portadores de $\mathrm{HbS}$, detectamos predomínio de indivíduos do sexo masculino e com mais de 29 anos. Outros pesquisadores encontraram resultados similares ao avaliar a prevalência de hemoglobinopatias em doadores de sangue na mesma cidade no período entre 2000 e 2009. Relataram maior positividade (62\%) em homens e em doadores na faixa etária de 31 a 44 anos (VALER et al., 2012). Bernieri; Fior e Ardenghi (2017) ao avaliarem a frequência de HbS em doadores de sangue no Rio Grande do Sul, também detectaram que os portadores do traço falcêmico eram na maioria $(60,8 \%)$ do sexo masculino.

De acordo com dados da ANVISA, em relação ao perfil do doador brasileiro, entre os anos de 2013 a 2016 houve predomínio de indivíduos do sexo masculino e com idade acima de 29 anos (ANVISA, 2018). Vários trabalhos confirmam esses dados. Martins et al. (2015), em Minas Gerais, encontraram $71 \%$ dos doadores do sexo masculino e 59\% acima de 29 anos. Vieira (2016) em pesquisa realizada no Distrito Federal detectaram 66\% de doadores homens e idade média de 34,1 anos. Santos e Macedo (2013) em pesquisa no Hemonúcleo de Campo Mourão-Pr, verificaram prevalência consideravelmente maior de doadores do sexo masculino em todas as idades, entretanto, com um perfil de doador mais jovem, entre 18 e 29 anos em ambos os sexos.

Estes dados indicam que no Brasil os homens são numericamente superiores na doação de sangue, provavelmente pelo sexo feminino apresentar algumas restrições, devido suas condições fisiológicas, tais como gravidez, lactação e menstruação (BERNIERI; FIOR; ARDENGHI, 2017). Quanto ao predomínio de doadores com mais de 29 anos pode ser porque os jovens não tenham se conscientizado ainda da importância da doação, entretanto, tal comportamento pode estar mudando, possivelmente devido as campanhas de doação.

A avalição do grau de escolaridade dos portadores de $\mathrm{HbS}$ teve como objetivo principal estimar a capacidade de acesso às informações disponíveis sobre o assunto. Pôde-se verificar que os indivíduos com maior grau de escolaridade doaram sangue com mais frequência, mesmo conhecendo sua condição, indicando que sabem que não há riscos para sua saúde e nem para os receptores, desde que os critérios de transfusão sejam respeitados.

Outro aspecto relevante neste trabalho, foi a tendência ao decréscimo da frequência de HbS nos últimos três anos de estudo. As políticas públicas adotadas em relação a doença falciforme devem ter contribuído no processo, inclusive a própria triagem pelos Bancos de Sangue. Bonzo (2013) reforça este aspecto, descrevendo o crescente esforço sanitário nos centros de doação de sangue no Brasil, em identificar e orientar portadores de HbS, possibilitando adequado aconselhamento genético, o que permite aos indivíduos ou famílias tomar decisões conscientes sobre a procriação. 
Nos centros de doação de sangue, o procedimento padrão após o exame positivo para $\mathrm{HbS}$, deve ser o convite para o aconselhamento genético através de uma carta, informando apenas a presença de uma característica genética e esclarecendo que os exames serão entregues na data pré-determinada. O processo ocorre em grupos com cerca de dez pessoas, cuja responsabilidade é do médico hematologista (DINIZ; GUEDES, 2005). O aconselhamento genético deve ser informativo e não coercitivo, dando liberdade para a futura escolha reprodutiva (FERREIRA; SILVEIRA-LACERDA; GARCÍA-ZAPATA, 2014).

Apesar da importância do aconselhamento genético, de forma geral, essa prática ainda é tímida em diversos países. No Brasil, onde o aborto é proibido, os centros de referência para doação de sangue têm se mostrado locais estratégicos para diagnóstico e captação de portadores do traço falciforme e aconselhamento genético, demonstrando que o processo educativo é a melhor forma de reduzir a propagação do gene da anemia falciforme (GUIMARÃES; COELHO, 2010; FERREIRA; SILVEIRA-LACERDA; GARCÍA-ZAPATA, 2014).

Não obstante todos os esforços e as políticas públicas adotadas em relação as doenças falciformes, este estudo detectou que 50,3\% dos indivíduos eram doadores pela primeira vez e, por sua vez, desconheciam serem portadores do traço falcêmico. Santos et al. (2015), triando hemoglobinopatias em população adulta no Ceará também detectaram que a maior parte $(66,67 \%)$ dos indivíduos desconhecia apresentar hemoglobinas variantes.

Como a ação efetiva do PNTN vem sendo realizada somente a partir de 2001, muitos indivíduos, hoje adultos, não realizaram o teste do pezinho ao nascimento (ou realizaram, mas sem a inclusão do rastreio para hemoglobinopatias) e ignoravam serem portadores do gene da $\mathrm{HbS}$. Por isso, a obrigatoriedade da realização dos testes em doadores de sangue é relevante, não somente para a segurança do receptor, mas, para detectar portadores do traço falciforme (DINIZ; GUEDES, 2005).

Cabe ressaltar que quanto mais cedo for realizada a triagem de hemoglobina variante $\mathrm{S}$, mais precocemente podem-se se instituir medidas que visem reduzir a morbimortalidade e prevenir sequelas nas formas homozigóticas SS, como também conduzir o aconselhamento genético dos indivíduos heterozigotos AS, abrindo espaço para essas pessoas serem informadas sobre o risco reprodutivo de gerarem crianças com doença falciforme (DINIZ; GUEDES, 2005; SILVA, 2017).

\section{CONCLUSÃO}

A prevalência encontrada para hemoglobina $S$ de $1,36 \%$ foi um resultado esperado quando comparado aos dados de outras pesquisas realizadas no Paraná e na região sul do país. O 
predomínio em caucasianos/brancos demonstrou a influência do contexto histórico na dinâmica populacional e no perfil genético da população estudada e, confirmaram o comportamento de miscigenação racial na região.

O predomínio de indivíduos do sexo masculino e com mais de 29 anos refletiu o perfil do doador de sangue no Brasil. Os portadores do traço falciforme com maior grau de escolaridade doaram sangue com mais frequência, provavelmente por terem mais acesso às informações e saberem que são hematologicamente e clinicamente saudáveis e aptos a doação de sangue.

A diminuição percentual mínima da ocorrência de $\mathrm{HbS}$ nos últimos três anos demonstra a eficácia das políticas públicas em relação as doenças falciformes, principalmente a triagem nos centros de referência de doação de sangue. Entretanto, este processo ainda é lento, havendo necessidade de mais investimentos públicos que permitam a detecção precoce de portadores do traço falcêmico e aconselhamento genético mais efetivo, como meio para evitar custos ao sistema de saúde e melhorar a qualidade de vida da população.

\section{REFERÊNCIAS}

ANVISA. Agência Nacional de Vigilância Sanitária. Manual de diagnóstico e tratamento de doenças falciformes. Brasília, DF, 2002.

ANVISA. Agência Nacional de Vigilância Sanitária. $5^{\circ}$ Boletim de Produção Hemoterápica. Brasília, DF, 2018.

AQUINO, F. C. et al. Estudo da correlação entre os níveis de AST, ALT e DHL e a presença de hemoglobina S no laboratório clínico da PUC Goiás. Revista Estudos (Goiânia), v. 41, n. 4, pp. 697-706, 2014.

BATISTA, A.; ANDRADE, T. C. Anemia falciforme: um problema de saúde pública no Brasil. Universitas Ciências da Saúde, v. 03, n. 01, pp. 83-99, 2005.

BERNIERI, T.; FIOR. D.; ARDENGHI, P. G. Prevalência de hemoglobina S em doadores de sangue do Hemocentro de Passo Fundo, Rio Grande do Sul, Brasil. Revista Brasileira de Pesquisa em Saúde (Vitória), v. 19, n. 4, pp. 104-108, 2017.

BONZO, M. E. A importância da triagem neonatal e do aconselhamento genético na doença falciforme. 2013. 33 F. Trabalho de Conclusão de Curso (Curso de Bacharelado em Medicina) Universidade Federal da Bahia - UFB, Salvador (BA), 2013.

BRASIL. Ministério da Saúde. Portaria $n^{0}$ 158, de 04 de fevereiro de 2016. Redefine o regulamento técnico de procedimentos hemoterápicos. Diário Oficial da República Federativa do Brasil, Brasília, nº 25, seção 1, p. 37, 05 de fevereiro de 2016.

DINIZ, D.; GUEDES, C. Confidencialidade, aconselhamento genético e saúde pública: um estudo de caso sobre o traço falciforme. Cadernos de Saúde Pública, v. 21, n. 3, pp. 747-755, 2005. 
FERREIRA, T. D.; SILVEIRA-LACERDA, E. de P.; GARCÍA-ZAPATA, M. T. A.

Aconselhamento genético para indivíduos com alterações das hemoglobinas e seus familiares: revisão sistemática de literatura. Revista da Escola de Enfermagem da USP, v. 48, n. 5, pp. 932-937, 2014.

GIBSON, J. S.; REES, D. C. How benign is sickle cell trait? EBioMedicine, v. 11, pp.21-22, 2016.

GUIMARÃES, C. T. L.; COELHO, G. O. A importância do aconselhamento genético na anemia falciforme. Ciências \& Saúde Coletiva, n. 15, Supl. 1, pp. 1733-1740, 2010.

JESUS, D. A. S. de; SANTANA, P. G. Anemia falciforme: um estudo de prevalência no Centro de Hemoterapia de Sergipe (Hemose). 2015. 20 F. Trabalho de Conclusão de Curso (Curso de Bacharelado em Enfermagem) - Universidade Tiradentes - UNIT, Aracajú (SE), 2015.

KRAWCZYK, A. M. et al. Prevalência de hemoglobina S por PCR-AE em pacientes do Laboratório Clínico da PUC Goiás. Revista Estudos (Goiânia), v. 41, n. 4, pp. 689-696, 2014.

MACHADO, L. de O. A anemia falciforme. 2014. 22 F. Trabalho de Conclusão de Curso (Especialização em Gestão em Saúde Pública) - Universidade Federal de Santa Maria - UFSM, Santa Maria (RS), 2014.

MARTINS, A. P. B. et al. Soroprevalência de doenças infecciosas em doadores de sangue do Hemocentro Regional de Cruz Alta - Rio Grande do Sul. Clinical \& Biomedical Research, v.35, n. 4, pp. 211-216, 2015.

MONTEIRO, A. C. B. et al. Anemia falciforme, uma doença caracterizada pela alteração no formato das hemácias. Saúde em Foco, n. 7, pp. 107-118, 2015.

MORAES, K. C. M.; GALIOTI, J. B. A doença falciforme: um estudo genético-populacional a partir de doadores de sangue em São José do Campos, São Paulo, Brasil. Revista Brasileira de Hematologia e Hemoterapia, v. 32, n. 4, pp. 286-290, 2010.

PEDRO, M, A. S.; PRIORI, A. Colonização e imigração no norte do paraná (1950-1980). In: SEED/PR. O professor PDE e os desafios da escola pública paranaense. Volume 1. Curitiba, 2010.

QUIARATI, J. B.; ZANUSSO JÚNIOR, G. Prevalência de portadores de hemoglobina S em população afrodescendente em Maringá-PR. Revista Uningá, v. 45, pp. 22-26, 2015.

RAMALHO, A. S.; GIRALDI, T.; MAGNA, L. A. Estudo genético-epidemiológico da hemoglobina S em uma população do sudeste do Brasil. Revista Brasileira de Hematologia e Hemoterapia, v. 30, n. 2, pp. 89-94, 2008.

REZENDE, L. M. S. L. Caracterização do traço falciforme, antígenos CDE e Kell em doadores de sangue da Fundação Hemocentro de Brasília. 2017. 12 F - Trabalho de Conclusão de Curso (Curso de Bacharelado em Biomedicina) - Centro Universitário de Brasília UniCEUB, Brasília (DF), 2017. 
RUIZ JUNIOR, E. Prevalência de hemoglobinopatias em recém-nascidos do município de

Giøânia-Goiânia. 2009. 59 F. Tese (Mestrado em Ciências da Saúde) - Universidade Federal de Goiás - UFG, Goiânia (GO), 2009.

SANTOS, M. C; MACEDO, L. C. Prevalência e perfil de doadores de sangue realizadas pelo Hemonúcleo de Campo Mourão-Pr. Revista Saúde e Pesquisa, v. 6, n. 1, pp. 8-12, 2013.

SANTOS, T. N. dos et al. Triagem para hemoglobinas variantes em população adulta no Estado do Ceará. Revista Guará, v. 3, n. 3, pp. 131-139, 2015.

SILVA, J. E. P. da; GIOVELLI, L. L. Traço falciforme: uma revisão para os centros de hemoterapia. Revista Saúde (Santa Maria), v. 36, n. 1, pp. 23-28, 2010.

SILVA, I. M. G. de A. Incidência das hemoglobinopatias diagnosticadas pelo teste do pezinho em um laboratório privado de João Pessoa - Pb no período de janeiro a junho de 2017. 2017. 50 F - Trabalho de Conclusão de Curso (Curso de Bacharelado em Farmácia) Universidade Federal da Paraíba - UFP, João Pessoa (PB), 2017.

SILVA, R. A. da et al. Estudo genético-populacional da doença falciforme a partir de doadores de sangue em Primavera do Leste-MT. Biodiversidade, v. 11, n. 1, pp. 108-114, 2012.

SOUZA, J. M. de et al. Fisiopatologia da anemia falciforme. Revista Transformar, n. 8, pp. 162-178, 2016.

VALER, T. S. P. et al. Hemoglobinopatias: prevalência em doadores de sangue. Revista Saúde e Pesquisa, v. 5, n. 1, pp. 27-34, 2012.

VIEIRA, A. G. Prevalência do traço falciforme em doadores de sangue do Distrito Federal. 2016. 15 F - Trabalho de Conclusão de Curso (Curso de Bacharelado em Biomedicina) - Centro Universitário de Brasília - UniCEUB, Brasília (DF), 2016. 